\section{Interrogando aos atores sociais: consumo com cidadania}

Fátima PORTILHO. Sustentabilidade ambiental, consumo e cidadania. São Paulo, Cortez, 2005. 255 páginas.

\section{Aloisio Ruscheinsky}

Interrogar os atores sociais no campo do consumo significa examinar o poder da cultura na trajetória das mudanças sociais. Com uma abordagem segundo a ótica do consumo, os cientistas sociais passaram a identificar nas práticas culturais mecanismos de poder na sociedade contemporânea. A competência e o comportamento de indivíduos e grupos sociais são trazidos para o centro das explicações sobre a subjetivação, a dominação social e a inovação tecnológica. Uma teoria da prática social é relevante para responder à questão crucial do imaginário e da avidez que suscita uma cultura de consumo. O consumo representa uma dimensão política fundamental da vida contemporânea ao ligar hábitos cotidianos aos impactos ambientais e ao alertar sobre riscos de diferentes naturezas para os consumidores.

A perspectiva de um modelo de sociedade sustentável conduz à apreciação da relação entre ética e desejos, produção e consumo, cidadania e práticas sociais, necessidades e supérfluos. A interrogação sobre estratégias, mediações e atores sociais é fundamental especialmente para a proposição de um desenvolvimento sustentável. Nesta perspectiva posiciona-se o livro Sustentabilidade ambiental, consumo e cidadania, que se apresenta como uma vasta revisão da literatura internacional oriunda de uma tese de doutorado. Com certeza passa a ser uma referência para ambientalistas e para o campo de análise da sociedade de consumo pela largueza e pertinência de sua abordagem.

Fátima Portilho pretende contribuir para a elaboração e o desenvolvimento de uma abordagem sociológica sobre consumo, especialmente para desvendar a existência e as debilidades de um ator social dotado pelo consumo. A autora apre- senta inicialmente a proposta da obra e procede a uma parcial revisão da literatura sobre a sociedade de consumo. Entre outros aspectos justifica a relevância e a proeminência da temática abordada, apontando que o tema do consumo no cenário ambientalista é cada vez mais central na agenda das ciências sociais. Em outros termos, as abordagens em torno do consumo estariam se encaminhando para alçar a hegemonia no debate dos problemas ambientais, na medida em que um novo discurso redefine a crise ambiental como um problema predominantemente originado nesse âmbito.

Esse enfoque suscita algumas questões, sintetizadas em seis pontos: 1) as ciências sociais possuem um posicionamento-chave para a interpretação dos riscos visíveis e invisíveis do consumo ampliado; 2) o crescimento perceptível e notório do consumo relativiza os posicionamentos de classe social, pois os efeitos dos riscos ambientais tendem a atingir quase indistintamente a população; 3) o potencial político a partir do consumo está condicionado à capacidade de desenvolver novas políticas híbridas, ou uma subpolítica, conforme Beck; 4) a análise lida com a consolidação da relevância das mediações e o declínio na legitimidade das instituições; 5) a sociedade no momento presente não se caracteriza mais de forma predominante pelo trabalho/produção, pelas classes sociais, mas antes pelo consumo que altera a qualidade de vida e pelos riscos a que todos estão submetidos cotidianamente; e 6) a emergência da sociedade de consumo, alicerçada na proeminência da ciência e da tecnologia e na abundância de bens, implica no fim das tradições, da natureza e da relativização das posições de classe.

A discussão empreendida neste livro aborda os limites implacáveis e as condições de possibilidade, sem deslizar para a crítica ao consumo supérfluo, alertando para os limites do consumo, a delimitação dos recursos naturais e a busca de uma racionalidade ambiental. Neste contexto, a autora define sua hipótese de trabalho: "as propostas de consumo sustentável restritas à esfera individual são limitadas, limitantes e desagregadoras. As ações de caráter coletivo podem ampliar as possibilidades de ambientalização e politização das relações de consumo, contribuindo para a construção da sustentabilidade e para a participação na esfera pública" (p. 36). Em outros termos, Portilho 
está à procura do lócus e dos atores sociais que congreguem as condições de possibilidade para assimilar o programa de mudanças que a urgência da agenda ambiental requer.

A construção do percurso do deslocamento discursivo, da produção para a esfera do consumo, a partir da emergência internacional do discurso político sobre consumo e meio ambiente, é o teor do segundo capítulo. A autora mostra que a regulação em grande medida está efetivada na produção e que a novidade em questões ambientais localiza-se na esfera do consumo, onde também se concentra o espaço de participação do cidadão. Intercalam-se, neste capítulo, de forma congruente, os resultados das conferências internacionais e a literatura acadêmica. Todavia, Portilho restringe-se quase por completo à literatura e ao contexto internacional do pensamento ambientalista, mas a realidade cruel com facetas locais pode apresentar outros meandros.

O terceiro capítulo dá conta da ampliação do enfoque sobre o consumo nas abordagens das ciências sociais e dos espaços institucionais onde se tratam das questões relativas aos efeitos ambientais da ciência e da tecnologia, das questões que a produção e o consumo proporcionam. Sob esta ótica, a autora realiza uma retrospectiva teórica relacionada à sociedade de consumo, a fim de melhor compreender a relação entre consumo, cultura, cidadania e meio ambiente. Para isso, destaca alguns elementos da compreensão e da justificação para se firmar a denominação de sociedade de consumo, bem como a emergência e a trajetória da propensão ao consumo.

O campo da natureza só faz sentido se passar pela esfera de compreensão humana e das relações sociais. Isto é endossado por diferentes vertentes, tanto por culturalistas, quanto pela vertente dialética materialista. Nesse sentido, a autora enfoca, em síntese, três diferentes maneiras de abordar a sociedade de consumo. É sobre essas teorias e suas perspectivas que convém firmar alguns comentários. A primeira vertente apresenta a perspectiva do consumo inserida na sociedade capitalista e subordinada à luta de classes, à predominância da mercadoria e do lucro. Nesta ótica, o consumidor é visto, acima de tudo, como vítima, explorado, manipulado e passivo. A segunda, como reverso da anterior, focaliza a sociedade de consumo como a ratificação da racionalidade e a consumação do utilitarismo. Ou seja, pela teoria de escolha autônoma do indivíduo, consumir é um ato racional por excelência, pleno de direito de escolha e poder. O terceiro enfoque caracteriza-se como pós-moderno; embora haja consenso quanto à perspectiva material e simbólica do consumo, essa vertente apresenta um olhar múltiplo da sociedade de consumo. A aquisição diferenciada de bens possui, segundo essa visão, a virtude de fortalecer laços e relações sociais, sendo o consumidor apreciado pela ótica do poder, da decisão, da identidade, da escolha e da subjetividade.

O quarto capítulo versa sobre o consumo na ótica do movimento ambientalista pós-Rio92, de um lado destacando dilemas, promessas, abrangência, armadilhas e ambigüidades das propostas de consumo verde que de alguma forma vem sendo absorvidas pelo mercado, e, de outro, as possibilidades das estratégias e os desafios conceituais e políticos do consumo sustentável. Três dimensões integram-se: produção justa, distribuição solidária e consumo sustentável. O documento "Agenda 21" poderia ter lugar de destaque na exposição dos argumentos, pois além de ter cunho internacional trata da mudança nos padrões de consumo e do desenvolvimento sustentável. Todavia, o texto fica devendo ao leitor a discussão dos dilemas inusitados e dos desafios políticos para que a formulação de proposições no campo ambiental transforme-se em resoluções práticas na sociedade civil.

O debate em torno da perspectiva ambiental modificou a visão sobre o desenvolvimento tecnológico e seus efeitos ambientais; hoje, há diferentes agentes sociais que endossam a sustentabilidade. Nesse sentido, as propostas de consumo sustentável no embate entre a esfera individual e as ações de caráter coletivo visando à politização e à ambientalização do consumo é a matéria do capítulo 5. Em vez de compreender a esfera do consumo pela lógica da submissão e da acomodação ao sistema, a autora pretende traçar as feições do consumidor como um ator social ou um cidadão ativo. Ao contrário da afirmativa de Canclini de que "cidadão do século XVIII e consumidor do século XXI", Portilho soma esforços para demonstrar que do papel de consumidor será 
viável a emergência do cidadão na sociedade de consumo. Para isso, contrapõe duas lógicas: a da despolitização pela dominância do mercado sobre a esfera pública, portanto, de cidadão a consumidor, e a lógica da politização, em que a partir do consumo abrem-se as condições para a emergência de atores sociais. Nesse percurso, a autora mantém-se sóbria na análise das conseqüências políticas do deslocamento da questão ambiental para o campo do consumo, mas se dedica aos limites, às possibilidades, às injunções, aos condicionamentos históricos, aos desafios e às ambigüidades da politização do consumo.

O movimento ambientalista de contestação ao consumo ou de boicote, sob um ponto de vista da crítica não é um movimento histórico, uma vez que em seu programa não cogita um projeto arrojado de sociedade alternativa. Ao longo dos anos, a consciência ambientalista levou as exigências ambientais a superarem a perspectiva monotemática, setorial e sectária. Na sua diversidade contempla temas centrais sobre problemas da modernidade, em que o consumo aparece entre os riscos ambientais.

Uma ambigüidade permanece no que diz respeito ao ponto de partida para a compreensão do movimento em suas características mais radicais: o discurso e a prática faz oposição ao consumo intenso e ampliado, ou os efeitos são maiores com a internalização da perspectiva ambiental em todos os âmbitos da sociedade? Para onde se encaminham as questões ambientais? Para O mundo da vida e suas relações cotidianas complexas ou para a construção de um novo modelo social pautado numa utopia de mudança?

De um lado, temos o significado da incorporação pelo público das reivindicações ambientais em situações sociais complexas, de outro, observase que o conhecimento de problemas ambientais produz comportamentos no público, mesmo que isso implique restrições às comodidades oferecidas pela sociedade de consumo. Será que o consumidor está disposto a "pagar o preço" para construir uma sociedade sustentável?

Ao contrário da retração das ciências sociais a respeito dessas questões, a autora defende a diversificação e a revitalização do campo da sociologia ambiental com ênfase na sociedade de consumo e no papel dos novos atores sociais. A análise, como um todo, aprofunda-se na crítica dessa sociedade, uma vez que a deterioração do meio ambiente causa impactos respeitáveis sobre a qualidade de vida. Atualmente, há uma compreensão cada vez maior sobre a relação entre abundância de consumo e racionalidade da qualidade ambiental, assim como o nexo entre as dimensões materiais e simbólicas do consumo.

A trajetória da teoria das necessidades de A. Heller, que a autora não aprecia em sua abordagem, poderia ser muito útil para a explicação da emergência da propensão ao consumo. Ainda mais, antes de eleger um novo pólo de irradiação ou endossar que a feição do consumo incita a produção, a partir de uma perspectiva dialética, é possível compreender que em cada circunstância a conjugação de fatores permite assinalar a influência mútua entre produção e consumo ou da preponderância de uma sobre a outra.

É necessário, creio, fazer um reparo às escolhas e ao enfoque da abordagem de Sustentabilidade ambiental, consumo e cidadania. Por certo, Marx e autores da escola de Frankfurt não apresentaram subsídios para compreender ao que hoje se caracteriza como sociedade de consumo, mas há outros autores sob influência da dialética ou da análise marxiana, também menos ortodoxos, que se dedicaram ao estudo do consumo na vertente dos eco-marxistas e dos eco-socialistas. A autora desconsidera contribuições contemporâneas, como Burkett, Foladori, Foster, Jameson, Leff, Lefevbre, Redclif, entre outros.

Se de um lado, a autora aponta para as novas condições e possibilidades da ação política na sociedade contemporânea, onde velhas instituições, mediações e mecanismos estão desgastados, de outro, o texto trata com parcimônia a abordagem do nexo entre a esfera estatal e a sociedade civil.

Em suma, considera as múltiplas abordagens da sociedade de consumo, mas não estabelece uma nítida distinção entre as vertentes que discordam e as que endossam que as questões ambientais engendradas pela sociedade de consumo podem também ser encaminhadas pela ciência e pelo mercado. Desse ponto de vista, tanto o mercado como o Estado estão ausentes na análise empreendida por Portilho. Quanto ao primeiro, embora a 
autora seja explícita na crítica das alternativas fáceis ou imediatas da sustentabilidade ambiental, não fica claro o suficiente como o consumo sustentável vai se relacionar com o mercado e seus poderosos mecanismos de marketing. Quanto ao Estado, sem dúvida, ele não aparece como regulador ou como espaço de negociação dos conflitos ambientais, por mais que se concorde com a crise institucional.

\section{ALOÍSIO RUSCHEINSKY é doutor em sociolo- gia pela USP, docente do Programa de Pós-Graduação em Ciências Sociais na Unisinos.}

\section{E-mail: aloisior@unisinos.br.} A gênese da sociedade excludente

Maristela SVAMPA. La sociedad excluyente: la Argentina bajo el signo del neoliberalismo. Buenos Aires, Aguilar/Altea/Taurus/Alfaguara, 2005. 352 páginas.

\section{Fabricio Pereira da Silva}

La sociedad excluyente é fruto de um longo trajeto percorrido pela socióloga argentina Maristela Svampa para compreender a Argentina contemporânea. A obra poderia ser entendida como uma síntese de seus trabalhos mais recentes. Aqui estão presentes elementos de diversos de seus estudos: sobre as transformações do peronismo nos anos de 1990 (em parceria com Danilo Martuccelli); sobre os metalúrgicos e a desestruturação do mundo do trabalho; sobre os bairros privados e countries e "os que ganharam" com a ascensão do neoliberalismo; e sobre os movimentos de desocupados e as assembléias de bairro (em parceria com Sebastián Pereyra). No entanto, mais que um mero amálgama da produção da socióloga na última década, esta obra é o ponto máximo em seus esforços para a compreensão da gênese da sociedade argentina atual. Se antes Svampa dedicou-se a focalizar diferentes aspectos do processo, agora ela lança um olhar panorâmico e oferece a seus leitores uma análise convincente do que define como "sociedade excludente".

Para Svampa, os primeiros ensaios de desmonte do que denomina "Estado nacionalpopular" ocorreram a partir de 1976, e, finalmente, a longa década neoliberal iniciada em 1989 na primeira gestão de Carlos Menem levou à gênese de uma "sociedade excludente" - construída com base em uma dinâmica de polarização e fragmentação social. Um "novo país" calcado em desigualdades cristalizadas. Para compreender esse processo, Svampa lança mão de suas pesquisas anteriores e de um notável levantamento da literatura acadêmica acerca dos diversos temas que aborda ao longo do livro. Seu caminho é cartesiano. Primeiro analisa as mudanças econômicas e políticas operadas na Argentina, em 